\title{
VULNERABILIDADE NATURAL À PERDA DE SOLO NA BACIA HIDROGRÁFICA DO RIO MARAPANIM, NORDESTE PARAENSE
}

\section{Tassio Koiti Igawa $^{1}$, Maria de Nazaré Martins Maciel $^{2}$}

1 Engenheiro Agrônomo graduado pela Universidade Federal Rural da Amazônia (tassio.igawa@gmail.com)

2 Professora Doutora do Instituto Ciberespacial da Universidade Federal Rural da Amazônia

Recebido em: 06/04/2018 - Aprovado em: 10/06/2018 - Publicado em: 20/06/2018 DOI: 10.18677/EnciBio_2018A84

\begin{abstract}
A vulnerabilidade natural à perda do solo é um elemento fundamental para realizar o planejamento ambiental, pois para tal procedimento é necessário que se tenha conhecimento prévio das características físicas da área estudada. Mediante a isso, o trabalho objetivou elaborar um estudo da vulnerabilidade para a bacia hidrográfica do rio Marapanim no nordeste paraense, a partir da identificação das áreas com maior ou menor propensão a perda natural do solo. Dessa forma, foi coletada uma serie de dados referentes às variáveis analisadas (geologia, geomorfologia, pedologia, declividade, uso e cobertura e clima), para posterior interação dos dados por meio da aplicação de álgebra de mapas, cujo resultado obtido foi a moderada e a mediana vulnerabilidade do solo. Portanto, pôde-se observar que a maior parte da bacia é composta por áreas moderadamente estáveis, sendo que obtiveram tal resultado por conta, principalmente, da elevada densidade da cobertura vegetal e pela boa estabilidade das variáveis pedologia, geologia e geomorfologia. Além disso, foi possível identificar a importância das geotecnologias para a construção do trabalho e a falta de dados com escalas mais detalhadas para obtenção de resultados com maior precisão.
\end{abstract}

PALAVRAS-CHAVE: Análise multicritério, álgebra de mapa, sistema de informações geográficas

\section{NATURAL VULNERABILITY TO EROSION IN THE MARAPANIM RIVER BASIN, NORTHEAST OF PARÁ STATE}

\begin{abstract}
The vulnerability of erosion is a fundamental element to carry out the environmental planning, because it is necessary to have prior knowledge of the physical characteristics at studied area. In this way, the objective of this work was to study the vulnerability of Marapanim river basin in northeast of Pará state, by means of the identification areas with a greater or lesser tendency to erosion. Thus, a series of data were collected on the analyzed variables (geology, geomorphology, pedology, slope, use and cover and climate) for later interaction of the data through the application of algebra map whose result obtained, it was moderate and medium vulnerability. Therefore, it was observed that most of the basin is composed of ENCICLOPÉDIA BIOSFERA, Centro Científico Conhecer - Goiânia, v.15 n.27; p.167 2018
\end{abstract}


moderately stable areas, and this result was obtained mainly due to the high density of vegetation cover and the high stability of pedology, geology and geomorphology variables. In addition, the importance of the geotechnologies for the accomplishment of the work and the lack of data with more detailed scales to obtain results with greater accuracy.

KEYWORDS: Multi-criteria analysis, Map algebra, Geographic information system

\section{INTRODUÇÃO}

O solo é um dos elementos principais para a realização das atividades agrícolas (MACHADO et al., 2017). Porém, é um recurso que pode ser esgotável, sendo que essa característica está diretamente ligada as atividades exercidas em seu uso (LEPSCH et al., 2015). Em vista disso, o estudo do solo, assim como, o estudo ambiental envolvendo esse recurso, viraram escopo de temáticas de pesquisas que envolvem o planejamento e ordenamento territorial, devido a isso está intimamente relacionado a qualidade de vida das pessoas o que acaba promovendo discussões diante a sociedade (ROVANI et al.,2015; ROVANI; VIEIRA, 2016).

O estudo da vulnerabilidade natural à perda do solo indicará o grau de susceptibilidade das áreas a qualquer tipo de dano existente e para conseguir encontrar esse indicativo é necessário que se tenha a compreensão do ambiente físico e social, para que isso possa servir como princípio na realização do planejamento ambiental (SANTOS; OLIVEIRA, 2013). Diante disso, é utilizada como instrumento importante utilizado pelos órgãos públicos, tendo em vista, o planejamento e a gestão territorial e ambiental (ROCKETT et al., 2014).

A bacia hidrográfica é composta por um grupo de terras drenadas por um rio e seus afluentes, ou seja, por uma rede de drenagem e é delimitada com base nas regiões mais altas do relevo denominadas de divisores de água (PEREIRA et al., 2016). Além disso, o termo bacia hidrográfica está sendo utilizado, como um elemento territorial e físico, com intuito de analisar a gestão e uso dos mananciais hídricos (COSTA et al, 2015).

A bacia hidrográfica do rio Marapanim passa por um intenso e acelerado processo de ocupação, ocasionando o desmatamento em regiões de conservação ambiental e em terras indígenas (LOUREIRO; PINTO, 2005). Diante disso, vê-se necessário a realização do estudo desta bacia com intuito de aplicar medidas mitigadoras a esses danos ambientais já consolidados.

O objetivo do trabalho foi elaborar um estudo da vulnerabilidade natural à perda de solo da bacia hidrográfica do rio Marapanim, através da análise integrada das características do meio físico, por meio do uso da metodologia de multicritério aditivo. A partir disso, identificar o diagnóstico da vulnerabilidade natural à erosão na área da bacia através dos critérios analisados.

\section{MATERIAL E MÉTODOS}

\section{Área de Estudo}

A bacia hidrográfica do Rio Marapanim (Figura 01) possui 2.296,22km² e está localizada no nordeste paraense entre as coordenadas $0^{\circ} 32 ' 19.075^{\prime \prime}$ e $1^{\circ} 18^{\prime} 36.961^{\prime \prime S ~ e ~} 47^{\circ} 31^{\prime} 45.232^{\prime \prime}$ e $48^{\circ} 2^{\prime} 20.954 " W$. Se faz presente em 11 municípios (Castanhal, Curuçá, Igarapé-Açu, Magalhães Barata, Maracanã, Marapanim, Santo 
Antônio do Tauá, São Caetano de Odivelas, São Francisco do Pará, Terra Alta e Vigia)

O rio principal dessa bacia é o Rio Marapanim com 127,96 km de extensão, sua nascente principal se encontra no município de São Francisco do Pará. A atividade econômica principal dessa região está voltada para agropecuária, pois de acordo com dados do Instituto Brasileiro de Geografia e Estatística - IBGE (2014) o Produto Interno Bruto dos municípios integrantes dessa bacia hidrográfica, majoritariamente advém da agropecuária.

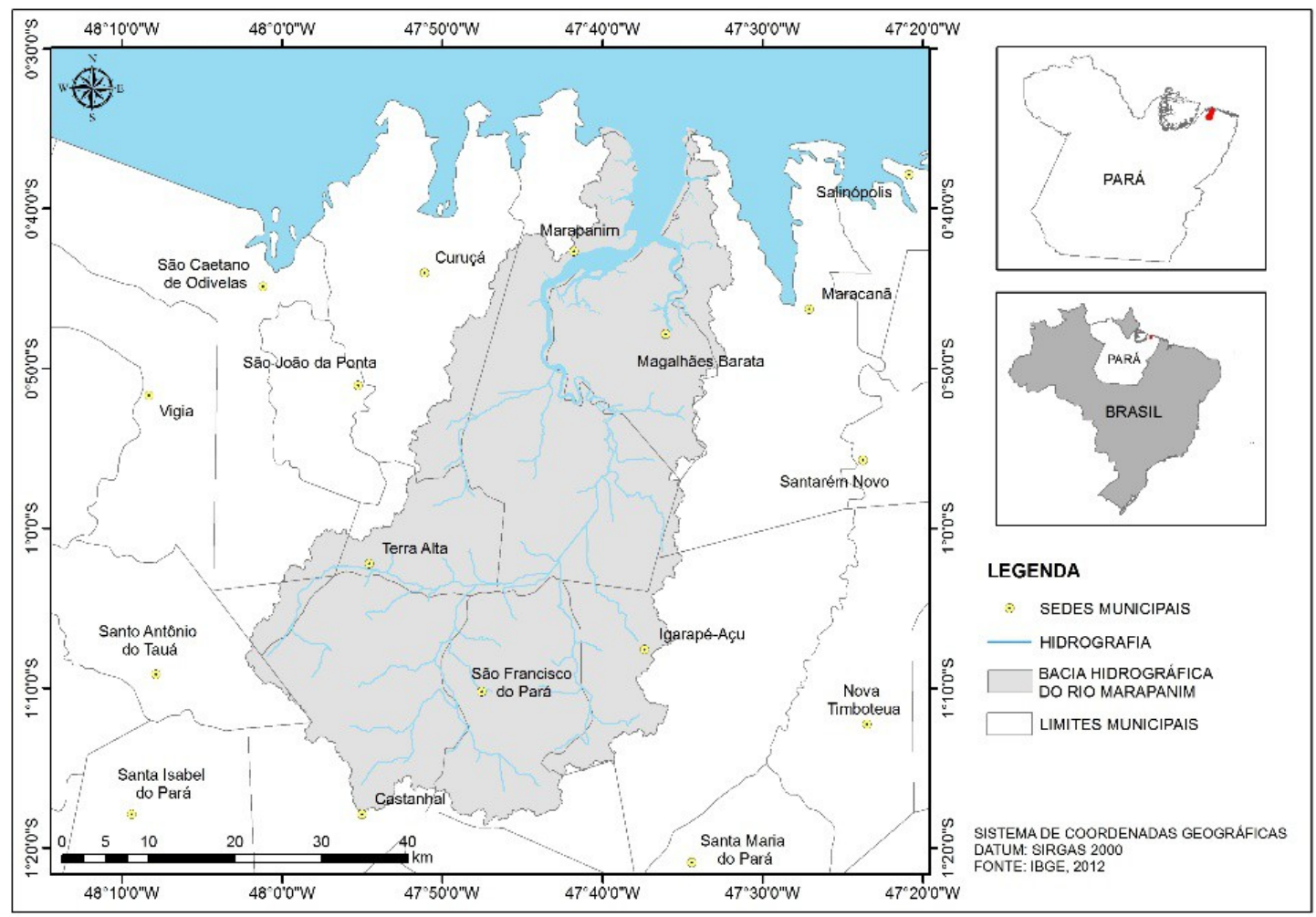

FIGURA 01: Localização da bacia hidrográfica do rio Marapanim, PA. Fonte: elaborado pelos autores.

\section{Materiais}

Foram utilizados os dados do Shuttle Radar Topography Mission (SRTM), com resolução espacial reamostradas a 30 metros, obtidas a partir da grade vetorial no banco de dados Topadata do INPE (http://www.webmapit.com.br), por meio das imagens do tipo Modelo Digital de Elevação (MDE) de número 01S49ZN, 01S48ZN e 00S48ZN, articulada às cartas na escala de 1:250.000. A delimitação da bacia hidrográfica e a extração da rede de drenagem foram utilizadas ferramentas do software ArcGis 10.1, especificamente o módulo Hidrology Modeling.

Para elaboração do mapa de cobertura vegetal e uso da terra utilizou-se o software Ecognition 9.2.1 Free Trial. Para isso foram utilizadas imagens do satélite Landsat 8/OLI referente às órbitas/ponto, 223/061 e 223/060, datadas do ano de 2016, obtidas no site do Serviço Geológico dos Estados Unidos.

Para os demais mapas utilizados no presente trabalho, foram utilizadas informações temáticas preexistentes. Para o mapa climático e de geologia, foram utilizados os dados da Companhia de Pesquisas de Recursos Minerais (CPRM) na escala de 1:1.000.000, já para os mapas de geomorfologia e de solos foram usados 
os dados do Instituto Brasileiro de Geografia e Estatística (IBGE) na escala de 1:250.000.

Com o intuito de realizar as operações que necessitam das unidades métricas, como a quantificação dos dados e a álgebra de mapas todos os dados foram projetados em sistema de coordenadas UTM, Datum SIRGAS 2000.

\section{Procedimentos Metodológicos}

Para a elaboração do mapa de vulnerabilidade natural à perda do solo é necessário realizar o estudo de todos os temas que influem na dinâmica ambiental e com base nisso, é imprescindível que seja definido os pesos para cada elemento dos respectivos temas, devido a isso, é de fundamental importância a utilização dos mapas intermediários com escopo de viabilizar a realização da mensuração dos dados referente à escala de vulnerabilidade.

\section{Unidades geológicas}

Com intuito de realizar a elaboração do estudo geológico da bacia hidrográfica do rio Marapanim, utilizou-se os dados obtidos da Companhia de Pesquisa de Recursos Minerais (2006), com escala de 1:1.000.000. Foi possível identificar que existem três tipos de unidade geológica na área estudada, as quais foram representadas na tabela $1 \mathrm{com}$ seus respectivos pesos. Sendo esses, definidos de acordo com os critérios estabelecidos por Crepani et al. (2001), os quais levam em consideração o tipo de rocha que a unidade geológica é constituída.

TABELA 1: Vulnerabilidade das unidades geológicas.

\begin{tabular}{cc} 
& Geologia \\
\hline Classe & Peso \\
\hline Grupo Barreiras & 2 \\
Depósito Aluvionares & 3 \\
Depósitos Litorâneos & 3 \\
\hline
\end{tabular}

Fonte: Adaptado de Crepani et al. (2001).

\section{Unidades geomorfológicas}

Para a análise geomorfológica da bacia estudada fez-se necessário a utilização do shapefile obtido no Instituto Brasileiro de Geografia e Estatística (2009), com escala de 1:250.000. Através dos dados adquiridos tornou-se possível identificar dois tipos de unidades geomorfológicas, as quais estão evidenciadas na tabela 2 com os respectivos valores de vulnerabilidade, foram definidos de acordo com as características de cada unidade geomorfológica, tiveram como base a relação entre a morfogênese e a pedogênese.

TABELA 2: Vulnerabilidade das unidades geomorfológicas.

\begin{tabular}{cc}
\hline \multicolumn{2}{c}{ Geomorfologia } \\
\hline Classe & Peso \\
\hline Acumulação Fluviomarinha & 1,3 \\
Dissecação Convexa & 1,5 \\
\hline
\end{tabular}

Fonte: Adaptado por Crepani et al. (2001). 


\section{Unidades pedológicas}

O estudo pedológico da área da bacia hidrográfica se deu pela aquisição dos dados do IBGE (2012) na escala de 1:250.000. Por conseguinte, foi possível identificar os tipos de solos presente na área, os quais estão expressos na tabela 3. Os pesos foram determinados de acordo com grau de maturidade de cada solo, seguindo Crepani et al. (2001).

TABELA 3: Vulnerabilidade das unidades pedológicas.

\begin{tabular}{cc}
\hline \multicolumn{1}{c}{ Pedologia } & \\
\hline Classe & Peso \\
\hline Latossolo Amarelo & 1 \\
Gleissolo & 3 \\
Solos Indiscriminados de Mangue & 3 \\
\hline
\end{tabular}

Fonte: Adaptado por Crepani et al. (2001).

\section{Declividade}

A elaboração dos dados de declividade foi realizada com a utilização do modelo digital de elevação, que foi construído a partir das imagens SRTM (Shuttle Radar Topography Mission) de 30 metros de resolução. Dessa forma, esses dados hipsométricos obtidos, possibilitaram a obtenção dos dados de declividade por meio da ferramenta slope do software ArcGis 10.1.

Diante dos dados gerados, houve a possibilidade de se realizar a quantificação das áreas referente aos respectivos intervalos de declividade, os quais foram definidos por Crepani et al. (2001) e evidenciados na tabela 4. Para essa mensuração houve a necessidade de utilizar a ferramenta reclassify, que viabilizou a redefinição dos intervalos de declividades já pré-estabelecidos e ocorreu a aplicação da ferramenta raster to polygon, com intuito de transformar o arquivo matricial em arquivo vetorial.

TABELA 4: Vulnerabilidade da declividade.

\begin{tabular}{cc}
\hline & Declividade (\%) \\
\hline Classe & Peso \\
\hline $0-2$ & 1 \\
$2-6$ & 1,5 \\
$6-20$ & 2 \\
$20-50$ & 2,5 \\
$>50$ & 3 \\
\hline
\end{tabular}

Fonte: Adaptado por Crepani et al. (2001).

\section{Cobertura vegetal e uso da terra}

A cobertura vegetal e uso da terra foram gerados a partir da classificação das imagens do satélite Landsat 8 , na qual se utilizou as imagens referentes a órbita/ponto, 223/061 e 223/060, a partir disso, foi realizada a classificação supervisionada orientada a objeto. Assim, foram definidas as classes agricultura anual, área urbana, campos naturais, dunas, pastagem e vegetação arbórea.

Dessa forma, definiram-se os pesos para cada classe de mapeamento de acordo com seu grau de estabilidade (CREPANI et al., 2001) como mostrado na Tabela 5, a qual considerou a densidade de cobertura vegetal presente, incluindo os usos da terra como as pastagens e a agricultura anual. 
TABELA 5: Vulnerabilidade do uso e cobertura.

\begin{tabular}{cc}
\hline \multicolumn{1}{c}{ Uso e cobertura da terra } \\
\hline Classe & Peso \\
\hline Agricultura anual & 2,5 \\
Área urbana & 3 \\
Campos naturais & 2,5 \\
Dunas & 3 \\
Pastagem & 2,5 \\
Vegetação arbórea & 1 \\
\hline
\end{tabular}

Fonte: Adaptado de Crepani et al. (2001).

\section{Intensidade pluviométrica}

O estudo climático se iniciou com a obtenção de dados de precipitação anual obtidos no CPRM (2013), que consiste em uma série histórica da precipitação média anual dos anos entre 1977 a 2006, os quais estão representados na escala de 1:1.000.000. Após realizar a quantificação da intensidade pluviométrica a partir da divisão da precipitação anual pelo número de meses do período chuvoso na região, que segundo Moraes et al. (2005) se estende de janeiro a agosto, foi possível definir duas classes de pesos distintos como é mostrado na tabela 6 .

TABELA 6: Vulnerabilidade para o tema clima.

\begin{tabular}{cc}
\hline \multicolumn{2}{c}{ Clima } \\
\hline Intensidade pluviométrica (mm/mês) & Peso \\
\hline $300-325$ & 2,1 \\
$325-350$ & 2,2 \\
\hline
\end{tabular}

Fonte: Adaptado de Crepani et al. (2001).

\section{Vulnerabilidade natural à perda do solo}

Os critérios seguidos para a criação da escala de vulnerabilidade, formulada por Crepani et al. (2001), foi concebida a partir das premissas da ecodinâmica elaborada por Tricart (1977). Dessa forma, definiram-se os valores de acordo com a avaliação da estabilidade das categorias morfodinâmicas, onde nas áreas que prevalecem a pedogênese estipularam-se valores próximos a 1, em situações de equilíbrio entre a morfogênese e pedogênese são atribuídos valores próximos a 2 , por fim, quando se tem predomínio da morfogênese são conferidos valores próximos a 3 .

Diante disso, este modelo foi implementado com a utilização das variáveis (Geologia, Geomorfologia, Pedologia, Declividade, Vegetação e Clima) a qual constituem cada elemento unitário básico do território, assim sendo, recebe-se um valor final referente à vulnerabilidade natural a perda do solo que, nesse caso, é resultante da média dos valores individuais de cada variável (Equação 1).

$V=\frac{p * G+p * R+p * S+p * V+p * C+p * D}{6}$

onde:

$V=$ Vulnerabilidade Natural à Perda de Solo

$\mathrm{G}=$ Critério Geologia

$\mathrm{R}=$ Critério Geomorfologia 
$S=$ Critério Solos

$\mathrm{Vg}=$ Critério Uso e Cobertura

$\mathrm{C}=$ Critério Clima

$\mathrm{D}=$ Critério Declividade

$p=$ Peso para cada critério

Vale ressaltar, que essas seis variáveis (geologia, geomorfologia, pedologia, declividade, uso e cobertura e clima) as quais foram utilizadas na elaboração do mapa final, atuam em diversos aspectos no que diz respeito a vulnerabilidade natural a perda do solo. Dessa forma, essas exercem contribuições específicas e distintas na bacia hidrográfica estudada, e com isso, foram definidos pesos distintos para cada fator como evidenciado na tabela 7.

TABELA 7: Influência das variáveis para a vulnerabilidade natural à perda do solo.

\begin{tabular}{cc}
\hline Fator & Peso \\
\hline Declividade & 3 \\
Clima & 3 \\
Uso e cobertura da terra & 2,5 \\
Pedologia & 2,5 \\
Geologia & 1,2 \\
Geomorfologia & 0,8 \\
\hline
\end{tabular}

Fonte: Elaborado pelos autores.

A elaboração do mapa de vulnerabilidade foi realizada por meio da álgebra de mapas no ambiente do software Arcgis 10.1, com a aplicação da Equação 1 e com isso obteve-se um mapa final que foi compatibilizado em uma escala de vulnerabilidade e, dessa forma, se fez possível a indicação do grau de vulnerabilidade dentro da área de estudo de acordo com a classificação expressa na tabela 8.

TABELA 8: Escala de vulnerabilidade.

\begin{tabular}{cc}
\hline Grau de vulnerabilidade & Valor final \\
\hline Estável & $1,0-1,3$ \\
Moderadamente estável & $1,4-1,7$ \\
Medianamente estável /vulnerável & $1,8-2,2$ \\
Moderadamente vulnerável & $2,3-2,6$ \\
Vulnerável & $2,7-3,0$ \\
\hline
\end{tabular}

Fonte: Adaptado de Crepani et al. (2001).

\section{RESULTADOS E DISCUSSÃO}

Neste tópico serão apresentados os resultados e análises referentes a cada critério estudado, bem como dos resultados da integração desses critérios resultando na vulnerabilidade natural à perda do solo.

\section{Geologia}

$\mathrm{Na}$ bacia hidrográfica do rio Marapanim foi possível identificar três tipos de unidades geológicas, o grupo barreiras, os depósitos aluvionares e os depósitos litorâneos. A formação barreiras representou $1.958,95 \mathrm{~km}^{2}(85,31 \%$ de toda área da 
bacia), foi classificada como medianamente vulnerável por ser composta de rochas sedimentares clásticas que segundo Crepani et al. (2001), consiste naquela cujo qual os agregados geralmente são friáveis ou físseis.

Os depósitos aluvionares e os depósitos litorâneos correspondem uma área respectivamente, de $237,96\left(10,36 \%\right.$ da área total) e $99,32 \mathrm{~km}^{2}(4,33 \%$ da área total), ambas as áreas são formadas por sedimento inconsolidado. Segundo Crepani et al. (2001), é considerada como a que possui menor grau de coesão dentre as rochas ígneas, metamórficas e sedimentares, devido a isso recebeu o maior índice de vulnerabilidade (peso 3).

\section{Geomorfologia}

As unidades geomorfológicas referentes a bacia hidrográfica do rio Marapanim possuem dois tipos de classes de relevo, a acumulação fluviomarinha e a dissecação convexa. A acumulação fluviomarinha de planície representou $16,51 \%$ da área total da bacia hidrográfica do Rio Marapanim. Essa unidade geomorfológica consiste em uma área plana que é formada pela associação entre a dinâmica de acumulação fluvial e marinha, que sazonalmente está sujeita a inundações, podem englobar manguezais, canais fluviais, deltas e cordões arenosos, sendo que essa unidade está situada nas regiões litorâneas próximas à foz de rios (IBGE, 2009).

A dissecação convexa, que compõe $83,49 \%$ da bacia estudada, é identificada por vertentes de declividade diversificada, por vales bem consolidados, esculpidas pelos canais ou cabeceiras de primeira ordem, essa unidade geomorfológica é formada geralmente, em rochas ígneas ou metamórficas dificilmente ocorre em rochas sedimentares (IBGE, 2009).

Contudo, pôde-se observar que a unidade geomorfológica referente à dissecação convexa é considerada como de média vulnerabilidade (peso 1,5), pelo fato de apresentar áreas com declividade diversificadas, enquanto que a acumulação fluviomarinha possui a vulnerabilidade baixa por ser caracterizada como de locais de área plana.

\section{Pedologia}

A partir da análise dos dados referente ao tipo de solo foi possível constatar que existem três tipos de solos na bacia estudada. Os Gleissolos compreendem uma área de $77,85 \mathrm{~km}^{2}$ na bacia hidrográfica, o qual representou 3,39\% da área total. Esse mesmo consiste em um solo com material mineral, o qual possui horizonte glei que pode se encontrar dentro da faixa dos $50 \mathrm{~cm}$ logo abaixo da superfície ou na profundidade de 50 a $150 \mathrm{~cm}$ depois do horizonte $A$ ou $E$ (apresentam ou não gleização) ou do horizonte hístico com espessura que impossibilita defini-lo como da classe dos organossolos (SANTOS et al., 2013).

O Latossolo Amarelo abrange uma área de $1.836,73 \mathrm{~km}^{2}$ na bacia hidrográfica do Rio Marapanim, cujo qual representa $79,99 \%$ da área total. Os Latossolos são solos com elevado grau de intemperização, bastante desenvolvidos resultantes de bruscas alterações no material constitutivo e geralmente, são solos profundos raramente possuindo profundidade inferior a $1 \mathrm{~m}$ (SANTOS et al., 2013).

Os solos indiscriminados de mangue são solos halomórficos compostos por sedimentos marinhos e fluviais, contendo matéria orgânica e que se localizam em regiões costeiras tendo influência constante do mar (PRADA-GAMERO et al., 2004) e são muito pouco desenvolvidos (EMBRAPA, 2017). Esses solos representam uma área de $381,42 \mathrm{~km}^{2}$ na bacia hidrográfica estudada o que representa $16,62 \%$ da mesma. 
A partir disso, como estabelecido por Crepani et al.(2001), foram atribuídos os valores de vulnerabilidade dos solos de acordo com seu grau de desenvolvimento, considerando o maior valor (peso 3 ) aos solos jovens e pouco desenvolvidos, já os solos com maior grau de maturidade receberam menor valor (peso 1). Diante dos conceitos supracitados associados aos critérios de vulnerabilidade, de acordo com o estabelecido por Crepani et al.(2001), os gleissolos receberam peso 3, latossolos peso 1 e os solos indiscriminados de mangue receberam peso 3 .

\section{Declividade}

A declividade é um dos principais elementos responsáveis pelo processo erosivo, pois a quantidade e a dimensão da partícula arrastada pela água vão depender da energia cinética que a mesma escorre e isso dependerá do comprimento de rampa e o grau de inclinação do terreno (GAMA, 2004). Dessa forma, a declividade está relacionada de forma diretamente proporcional à susceptibilidade a erosão.

Crepani et al.(2001), o grau de declive do terreno possui uma direta relação com a velocidade de conversão de energia potencial em energia cinética, dessa forma, os locais que apresentam reduzidos ângulos de inclinação se tem uma prevalência da pedogênese, enquanto que em regiões com maior declividade há um predomínio da morfogênese.

A declividade na área estudada mostrou que grande parte apresenta muito baixa ou baixa declividade, já que representam respectivamente, 45,69 e $46,4 \%$, ou seja, somente essas duas classes morfométricas compõem $92,08 \%$ de toda a área da bacia. Já as regiões de média e alta declividade por essa ordem correspondem 7,92 e $0,003 \%$. Diante disso, a declividade obterá uma menor influência em relação a susceptibilidade a perda do solo. Junior et al. (2013), Rodrigues et al. (2016) e Santos et al. (2017) estudando bacias do Nordeste Paraense, puderam observar, que mais de $80 \%$ da área total dessas bacias apresentaram declividades abaixo de $8 \%$.

\section{Uso e cobertura da terra}

A cobertura vegetal atua na proteção natural do solo contra a erosão, pois promove a redução da intensidade do impacto das chuvas, haja vista que impede a ocorrência do contato direto das gotículas de água com o solo, além disso, através da implementação da matéria orgânica advinda da biomassa produzida por essa vegetação é que se tem o aumento da retenção de água no solo (GAMA, 2004).

Em vista disso, foi identificado que na bacia hidrográfica estudada mais da metade é composta por vegetação arbórea ( $56,64 \%$ da área total), ou seja, possui uma elevada densidade de cobertura vegetal o que a conferiu o peso 1 , que consiste no de menor susceptibilidade a erosão. Também foram encontradas área como os campos naturais com $1,9 \%$ da área, e dunas com $0,32 \%$ da área da bacia. Foram mapeadas também as áreas formadas pela ação antrópica como agricultura $(3,15 \%)$, área urbana $(1,27 \%)$ e pastagem $(36,72 \%)$.

\section{Clima}

A chuva é um dos elementos climáticos de maior importância quando se estuda a erosão do solo, pois quanto maior a taxa pluviométrica em um intervalo de tempo, maior será a perda por erosão (GAMA, 2004).

A bacia hidrográfica do Rio Marapanim possui uma intensidade pluviométrica intermediaria, com $27,17 \%$ da área da bacia na faixa de 300 a $325 \mathrm{~mm} / \mathrm{mês}$ e 
$72,83 \%$ entre 325 a $350 \mathrm{~mm} / \mathrm{mês}$. Diante disso, é nítida a influência do clima no que diz respeito a susceptibilidade à perda do solo, pois é evidente a presença de áreas com valores significantes em relação a intensidade pluviométrica.

\section{Vulnerabilidade natural à perda de solo}

O mapa de vulnerabilidade que é o produto deste trabalho consiste em um documento cartográfico resultante da análise integrada referente à geologia, geomorfologia, pedologia, declividade, uso e cobertura da terra e clima. Diante disso, se tornou viável a identificação e quantificação das áreas com maior ou menor propensão a erosão como evidenciada na tabela 9 e figura 2, onde observa-se que na bacia do rio Marapanim não existem áreas totalmente estáveis ou totalmente vulneráveis a perda natural do solo. A bacia se encontra com grau de estabilidade de moderado a mediano. Este resultado expressa a tendência natural de equilíbrio entre os processos de pedogênese e morfogênese, resultantes das múltiplas combinações entre seus fatores naturais, e a interferência do fator antrópico, ocasionador do desequilíbrio.

TABELA 9: Distribuição das classes referente ao grau de vulnerabilidade.

\begin{tabular}{ccc}
\hline Grau de vulnerabilidade & Área $\left(\mathrm{km}^{2}\right)$ & $\begin{array}{c}\% \text { da } \\
\text { Bacia }\end{array}$ \\
\hline Estável & - & - \\
Moderadamente estável & $1.488,20$ & 64,81 \\
Medianamente estável/ vulnerável & 807,95 & 35,19 \\
Moderadamente vulnerável & - & - \\
Vulnerável & - & - \\
\hline
\end{tabular}

Fonte: Elaborado pelos autores.

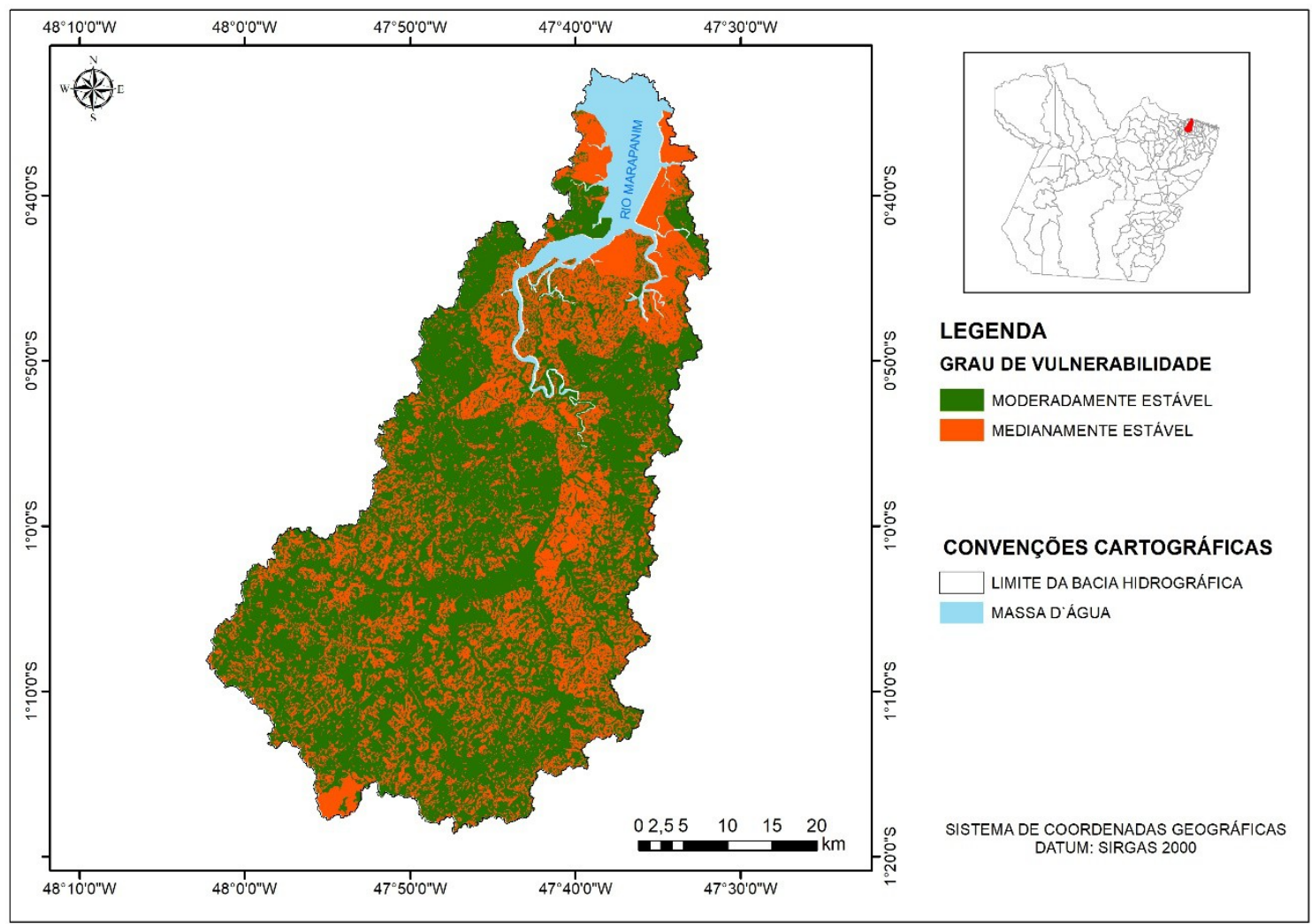

FIGURA 2: Vulnerabilidade natural à perda de solo. Fonte: elaborado pelos autores. 
A partir da figura 2, observa-se a distribuição espacial das referidas classes qualitativas de vulnerabilidade natural à perda de solo. Dessa forma, ficou evidente que as áreas moderadamente estáveis estão situadas em grande parte, nos locais de declividade baixa, em latossolo amarelo, apresentando elevada densidade de cobertura vegetal, na formação geológica barreiras e na unidade geomorfológica dissecação convexa.

Já nas áreas com grau de estabilidade medianamente estável foi possível identificar na figura 2, que se localizam, principalmente, nos locais com solos indiscriminados de mangue ou em áreas com baixa densidade de cobertura vegetal, como as classes de pastagem, área urbana e dunas. Por conta disso, se apresentam com o maior grau de vulnerabilidade na bacia hidrográfica do rio Marapanim.

\section{CONCLUSÃO}

O mapa de vulnerabilidade natural à perda do solo possibilitou identificar que a bacia hidrográfica do rio Marapanim é composta de áreas com moderada ou mediana estabilidade, sendo que as variáveis uso e cobertura e pedologia foram preponderantes na diferenciação desses dois graus de vulnerabilidade identificados na bacia.

A geotecnologia se fez como um instrumento imprescindível nas análises ambientais realizadas neste trabalho. Pois, por meio da álgebra de mapas foi possível realizar essa integração de variáveis que compõem a dinâmica ambiental.

Vale ressaltar a falta de dados com escalas de melhor qualidade, ou seja, com escalas maiores, para realizar a elaboração de trabalhos com maior precisão, principalmente, em relação aos dados de precipitação, geomorfologia e geologia.

Por fim, esse estudo poderá ser utilizado para fins de planejamento ambiental, pois foi possível identificar as áreas mais susceptíveis à perda de solo na bacia hidrográfica estudada.

\section{REFERÊNCIAS}

COSTA, F.E.V. da; SANTOS, N.S.L. dos; RODRIGUES, J.I.L. Apropriação da Natureza para Fins Econômicos e Problemáticas Ambientais da Bacia do Rio PeixeBoi na Cidade de Peixe-Boi (PA.). Revista do Instituto Histórico e Geográfico do

Pará (IHGP), v.2, n.2, p. 22-34, $2015 . \quad$ Disponível em:<http://dx.doi.org/10.17553/2359-0831/ihgp.v2n2p22-34. doi:10.17553/23590831/ihgp.v2n2p22-34.

CPRM. Serviço Geológico do Brasil. 2006. Disponível em:< http://geobank.cprm.gov.br/>. Acesso em: 28 dez. 2016.

CPRM. Sistema Nacional de Informações sobre Recursos Hídricos. 2013. Disponível em:<http://www.snirh.gov.br/arcgis/rest/services/SNIRH2016/Precipitacao_isoietas/M apServer?f=kmz>. Acesso em: 28 dez. 2016.

CREPANI, E. M.; MEDEIROS, J. S. de; HERNANDEZ FILHO, P.; FLORENZANO, T. G.; DUARTE, V.; BARBOSA, C. C. F. Sensoriamento remoto e geoprocessamento aplicados ao Zoneamento Ecológico-Econômico e ao ordenamento territorial. São José dos Campos: 2001. 124 p. 
EMBRAPA. Agência Embrapa de Informação Tecnológica. Disponível em:< http://www.agencia.cnptia.embrapa.br/gestor/territorio_mata_sul_pernambucana/arv ore/CONT000gt7eon7j02wx7ha087apz2c3xd0do.html>. Acesso em: 16 fev. 2017.

GAMA, J.R.N.F. Solos: Manejo e interpretação. Belém: Embrapa Amazônia Oriental, 2004. 183 p.

IBGE - Instituto Brasileiro de Geografia e Estatística, 2014. Disponível em:< https://cidades.ibge.gov.br/>. Acesso em: 22 jan. 2017.

IBGE - Instituto Brasileiro de Geografia e Estatística, 2009. Disponível em:<

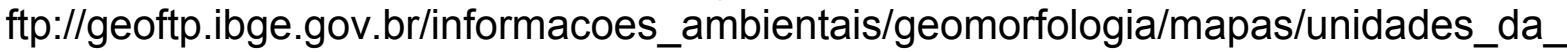
federacao/pa_geomorfologia.pdf>. Ācesso em: 28 dez. 2016.

IBGE - Instituto Brasileiro de Geografia e Estatística, 2012. Disponível em:< http://www.geoservicos.ibge.gov.br/geoserver/>. Acesso em: 16 set. 2016.

INPE. Projeto TOPODATA. Disponível em:<http://www.dsr.inpe.br/topodata/>. Acesso em: 28 dez. 2016.

JUNIOR, A. C. R. A. Fatores de risco a inundação na bacia hidrográfica da Estrada Nova Belém - PA. Geografia (Londrina), v. 22, n. 2. p. 57-78, maio/ago. 2013. Disponível em:< http://www.uel.br/revistas/uel/index.php/geografia/article/view/12108>.

LOUREIRO, V. R.; PINTO, J. N. A. A questão fundiária na Amazônia. Estudos Avançados, São Paulo, v. 19, n. 54, p. 77-98, mai./agos. 2005. Disponível em:< http://dx.doi.org/10.1590/S0103-40142005000200005 >. doi: $10.1590 /$ S0103-40142005000200005

LEPSCH, I.F.; ESPINDOLA, C.R.; FILHO, O.J.V.; HERNANI, L.C.; SIQUEIRA, D.S. Manual para Levantamento utilitário e classificação de terras no sistema de capacidade de uso. Viçosa, MG: 2015. 170 p.

MACHADO, L.N.; LOSS, A.; BACIC, E.L.Z.; DORTZBACH, D.; LALANE, H. de C. Vulnerabilidade à perda de solo na microbacia Lajeado Pessegueiro, Brasil. Scientia Agropecuaria, v. 8, n.2, p.159-168, 2017. Disponível em:< http://dx.doi.org/10.17268/sci.agropecu.2017.02.08>.doi:10.17268/sci.agropecu.2017 .02.08.

MORAES, B. C.; COSTA, J.M.N. da; COSTA, A.C.L. da; COSTA, M.H. Variação espacial e temporal da precipitação no estado do Pará. Acta Amazonica, v.35, p. 207-214, 2005. Disponível em:< http://dx.doi.org/10.1590/S004459672005000200010>. doi: 10.1590/S0044-59672005000200010.

PEREIRA, P.R.M.; RODRIGUES, T.C.S.; VIEGAS, J.C.V. Diagnóstico ambiental e caracterização morfométrica das Microbacias Hidrográficas de Pedro do Rosário, Amazônia Maranhense (Brasil) $^{*}$. Revista Brasileira de Gestão Ambiental e Sustentabilidade, v.3, n.5, p. 153-163, 2016. Disponível em:<http://dx.doi.org/10.21438/rbgas.030505>. doi: 10.21438/rbgas.030505. 
POELKING, E.L.; DALMOLIN, R.S.D.; PEDRON, F.A.; FINK, J.R. Sistema de informação geográfica aplicado ao levantamento de solos e aptidão agrícola das terras como subsídios para o planejamento ambiental do município de Itaara, RS. Revista Árvore, Viçosa-MG, v. 39, n.2, p. 215-223, 2015. Disponível em:< http://dx.doi.org/10.1590/0100-67622015000200001. doi: 10.1590/010067622015000200001.

PRADA-GAMERO, R. M.; VIDAL-TORRADO, P.; FERREIRA, T. O. Mineralogia e físico-química dos solos de mangue do rio Iriri no canal de Bertioga (Santos, SP). Revista Brasileira de Ciência do Solo, v.28, n. 2, p. 233-243. 2004. Disponível em:< http://dx.doi.org/10.1590/S0100-06832004000200002>. Acesso em: 10.1590/S0100-06832004000200002.

RODRIGUES, R.S.S.; FERNANDES, L.L.; CRISPIM, D.L.; VIEIRA, A.S. de A.; PESSOA, F.C.L. Caracterização morfométrica da bacia hidrográfica do Igarapé da Prata, Capitão Poço, Pará, Brasil. Revista Verde de Agroecologia e Desenvolvimento Sustentável. v.11, n. 3, p. 143-150, 2016. Disponível em:< http://dx.doi.org/10.18378/rvads.v11i3.4313>. doi: 10.18378/rvads.v11i3.4313.

ROCKETT, G.C.; MARTINS, E.M.; TODT, V.; THUM, A.B.; BARBOZA, E.G. Geoprocessamento aplicado à análise ambiental: Vulnerabilidade natural à perda de solo no Morro do Osso, Porto Alegre/RS. GEOGRAFIA, Rio Claro, v.39, n.3, p. 465481, 2014. Disponível em:<https://www. researchgate.net/profile/Gabriela_Rockett/publication/272791059_Geoprocessament o_aplicado_a_Analise_Ambiental_Vulnerabilidade_Natural_a_Perda_de_Solo_no_M orro_do_Osso_Porto_AllegreRS/links/54ee5b090cf25238f93a3664/Geoprocessamen to-aplicado-a-Analise-Ambiental-Vulnerabilidade-Natural-a-Perda-de-Solo-no-Morrodo-Osso-Porto-Alegre-RS.pdf>.

ROVANI, F.F.M.; CASSOL, R.; WOLLMANN, C.A.; SIMIONI, J.P.D. Análise da vulnerabilidade natural à perda de solo de Barão de Cotegipe, R.S. Revista do Departamento de Geografia, v. 29, p. 262-278, 2015. Disponível em:< http://dx.doi.org/10.11606/rdg.v29i0.102085>. doi: 10.11606/rdg.v29i0.102085.

ROVANI, F.F.M.; VIEIRA, M. Vulnerabilidade natural do solo de Silveira Martins RS. Revista Floresta e Ambiente, v. 23, n.2, p. 151-160, 2016. Disponível em:< http://dx.doi.org/10.1590/2179-8087.125614>. doi: 10.1590/2179-8087.125614.

SANTOS, J.G.; OLIVEIRA; L.A. Fragilidade ambiental da bacia hidrográfica do Ribeirão São Bento da Ressaca, Município de Frutal - MG. Revista Eletrônica de Geografia, v.5, n. 15, p. 02-23, 2013. Disponível em:< http://www.observatorium.ig.ufu.br/pdfs/5edicao/n15/01.pdf>.

SANTOS, L.L.M. dos; RODRIGUES, R.S.S.; BITTENCOURT, G.M. Morfometria das bacias hidrográficas dos rios Caraparu e Maguari-Açú, Região Metropolitana de Belém, Pará, Brasil. Revista Brasileira de Gestão Ambiental. v. 11, n. 1, p. 66-75, 2017. Disponível em:< http://dx.doi.org/10.18378/rbga.v11i1.4747>. doi: 10.18378/rbga.v11i1.4747. 
TRICART, J. Ecodinâmica. Rio de Janeiro: FIBGE, Secretaria de Planejamento da República, 1977. 97p.

USGS. Earth Explorer. Disponível em:<https://earthexplorer.usgs.gov/>. Acesso em: 14 set. 2016. 